\title{
Secondary Transition of Multicultural Learners: Lessons from the Navajo Native American Experience
}

\author{
Lynn K. Wilder
}

Aaron P. Jackson

Brigham Young University, aaron_jackson@byu.edu

Timothy B. Smith

Brigham Young University, tbs@byu.edu

Follow this and additional works at: https://scholarsarchive.byu.edu/facpub

Part of the Counseling Psychology Commons

\section{Original Publication Citation}

Wilder, L., Jackson, A., \& Smith, T. B. (2001). Secondary transition of multicultural learners:

Lessons from the Navajo Native American experience. Preventing School Failure, 45, 119-124.

\section{BYU ScholarsArchive Citation}

Wilder, Lynn K.; Jackson, Aaron P.; and Smith, Timothy B., "Secondary Transition of Multicultural Learners: Lessons from the Navajo Native American Experience" (2017). Faculty Publications. 2008.

https://scholarsarchive.byu.edu/facpub/2008 
Multicultural Transition

Wilder, L., Jackson, A., \& Smith, T. B. (2001). Secondary transition of multicultural learners: Lessons from the Navajo Native American experience. Preventing School Failure, 45, 119-124.

Secondary Transition of Multicultural Learners:

Lessons From the Navajo Native American Experience

Lynn K. Wilder

Aaron P. Jackson

Timothy B. Smith 
Abstract

Special educators typically individualize services according to student disability; they should also individualize services according to student culture. Culture influences postsecondary outcomes for students with disabilities (Bakken \& Aloia, 1999). This article identifies 4 barriers to successful transition for Navajo Native American students and suggests strategies for teachers to use to minimize the risks of unsuccessful transition for multicultural students. The article provides information that special educators can use to better individualize their transition services to all students with disabilities. 
Introduction

The Individuals with Disabilities Act of 1990 (IDEA), P.L. 101-476, and IDEA Amendments of 1997, P.L. 105-17, mandate a transition planning program of studies for students beginning at age 14 and transition planning services for all students with disabilities ages 16 and older. The phrase "all students with disabilities" is interpreted to mean that regardless of the type of disability, students should receive transition services. Clearly, a student's type of disability will impact the specific issues he/she faces in postsecondary transition. By considering the context of a student's type of disability, special educators can better individualize planning for successful transitions. Such individualization is a guiding principle in the field of special education (Smith, 1998). However, individualization based on disability classification alone is insufficient to facilitate successful postsecondary transitions for all students with disabilities.

In addition to the contexts that result from different types of disabilities, special educators should consider students' cultural contexts. Culturally sensitive special education services can enhance the likelihood of successful postsecondary transitions because culture does influence postsecondary outcomes (Bakken \& Aloia, 1999). By recognizing cultural influences, teachers can better individualize services. 
Individualization should be based on disability classification and cultural context.

Despite the tone of equality and fairness present in the phrase "all students with disabilities," statistics reveal alarmingly inequitable trends in the field. Minority ethnic groups are overrepresented in special education classes (Baca \& Cervantes, 1998; Smith, 1998). Students from these groups are more likely to be misdiagnosed and to receive inadequate services once they are diagnosed (Obiakor, 1999). School dropout rates of youth from some cultures are five times higher than those of White students (Minnesota Private College Research Foundation, 1994). Similarly, high incarceration rates and other negative trends indicate some serious problems in the transition of some students from diverse cultures to the world of work or postsecondary training (National Council of Juvenile and Family Court Judges, 1990).

These aforementioned problems have been widely reported, and they speak to the imbalance of power within society as a whole. As Gibson (1991) pointed out:

[A minority group is] a group occupying a subordinate position in a multiethnic society, suffering from the disabilities of prejudice and discrimination, and maintaining a separate group identity. Even though individual members of the group may improve their 
social status, the group itself remains in a subordinate position in terms of its power to shape the dominant value system of the society or to share fully in its rewards. (p. 358)

Whenever there are imbalances of power, there tend to be imbalances in opportunities and outcomes. Although there is a tendency for those in power to minimize and blame minority groups for their own misfortune, labeling and fault-finding have not been shown to be effective methods for improving educational outcomes. Educational outcomes have been shown to improve among minority youth when educators and employers become aware of multicultural issues and modify their practices accordingly (Sue \& Sue, 1999; McIntosh, 1998; Winzer \& Mazurek, 1998).

This article describes the impact of culture and cultural differences in school and work; it also discusses the importance of enhancing multicultural awareness and identifies common obstacles to minority students in postsecondary transitions. In addition, it presents a recent study that focuses on the experience of Navajo Native Americans in transition. The purpose is to provide information that special educators can use to better individualize their transition services to all students with disabilities.

\section{Culture and Cultural Differences}


Culture is more than race or ethnicity. It includes one's beliefs, values, expectations, customs, and perceptions. Culture is a pervasive influence on behavior. A student's culture can be related to country of origin, religious beliefs, neighborhood, group affiliations, socioeconomic status, and extended family influences.

Similarly, schools and workplaces are characterized by particular cultures, including sets of beliefs, values, customs, and behaviors. Teachers, administrators, and employers all set certain expectations (e.g., be on time to class and do your best). Understanding these cultures and adapting to expectations and guidelines are important skills for students to master if they are to be successful within those settings. However, sometimes school and work cultures can hold expectations and require ways of doing things that are different from what the students have learned elsewhere.

Cultures vary greatly, and when the particular culture of a student varies significantly from the culture of the school system or the workplace, the result can be confusion, misunderstanding, or even hostility. The wide range of behavioral differences exhibited by students in schools is partially attributable to different cultural orientations. Over $35 \%$ of public school children in the United States are from an ethnic minority group, with at least 20 unique ethnic 
backgrounds being represented in most states (Hoyt, 1988; Winzer \& Mazurek, 1998). Special educators can best facilitate student adaptation to school and work environments when they themselves are aware of the particular challenges and concerns that may arise for diverse students.

Multicultural Awareness

Given the diversity of contemporary North American society, the need for accommodation and adaptation in special educational strategies is clear. Strategies useful for some geographic regions or cultural groups may not be effective in other contexts. In fact, some strategies may be harmful when implemented without consideration of local education and employment contexts (Sue, 1999; Sue \& Sue, 1999).

The professional literature has recognized that cultural contexts do impact the educational outcomes of students of color (Ornstein \& Levine, 1989), therefore, the need exists to train special educators in effective multicultural service delivery (Voltz, 1998). Moreover, the literature has recognized that specific awareness, knowledge, and skills are necessary to work successfully with members of any specific ethnic group (Baca \& Cervantes, 1998; Winzer \& Mazurek, 1998). However, many special educators have yet to recognize their own cultural biases and limitations in this area. 
Awareness of multicultural issues begins with a personal examination of one's own values, beliefs, and possible biases (Sue \& Sue, 1999). People can best understand others when they first realize that they are subject to cultural influences. If they see themselves as products of and contributors to a culture, it is easier to see others in their cultural contexts as well. Thus they recognize that because they function within a culture, they are all equal despite their differences. Conversely, when they fail to see that their actions are influenced by the values and assumptions of their own culture, it is easy to dismiss or denigrate the actions of those who differ from them due to the values and assumptions of another culture. For example, a special educator may unknowingly give preferential treatment to students who share her/his value of deference to authority, and students whose cultures emphasize egalitarian and interdependent relationships may be less favorably received when they approach the teacher as they would a friend. Awareness of cultural differences can lead to openly discussing values or to adapting both sets of values to be more compatible. In this case, the special educator could either explain her/his expectations and then practice formal language with new students or else modify his/her expectations and learn to feel comfortable with informality and mutual interchange. 
Because lack of cultural awareness is now less common than superficial awareness, several authors express concern that many educators and administrators fail to recognize the limitations of their awareness (Easter, Shultz, Neyhart, \& Reck, 1999; Howitt \& Owusu-Bempah, 1999; Katz \& Torres, 1983; McIntosh, 1998; Sue \& Sue, 1999). They argue that unrecognized superficiality in cultural awareness can be as problematic as a lack of awareness. Unrecognized superficiality is more resistant to change than lack of cultural awareness because people who sincerely believe that they are helping others fail to make changes that are really necessary to keep their "help" from being detrimental.

Recognizing Biases and Mistrust

A term often used in the literature to describe continuation of unintentional mistreatment is "White privilege" (McIntosh, 1998). Because people in socially dominant ethnic groups (Caucasians in North America) do not experience pervasive discrimination, they fail to account for their influences on the perceptions and actions of those who do. The typical North American Caucasian takes for granted that he/she will be seen by others as an individual and not prejudged on the basis of his/her ethnicity, be understood by others, be surrounded by others with similar appearance, speech, values, etc. These perceptions and expectations are not shared by people who 
experience discrimination. But because many European Americans take for granted the privilege of being treated fairly, they misunderstand or misinterpret the actions of those who perceive themselves as being treated unfairly.

This subtle assumption becomes particularly problematic when "acting like everyone else" in North American society really means "acting White." Western European values, such as individualism and materialism, are then implicitly imposed upon all Americans, regardless of their background. Thus, it is not uncommon for minority ethnic groups to be negatively labeled when they do not "succeed" according to individualistic and materialistic values. From a perspective that acknowledges White privilege, such negative labeling reinforces the dominance of European Americans by denying the values of other groups, such as collectivism and holism.

When a special educator is not a member of the groups he/she teaches, members of the groups may see the teacher as an "outsider" who cannot understand their situation, or they may perceive the teacher as patronizing or paternalistic. Parents sometimes feel that because their children were singled out for special services, the teacher must be racist. Involving parents and community in the planning and implementation of programs designed to assist certain students can facilitate effective 
intervention efforts and reduce the likelihood of mutual distrust.

For every challenge facing even a multiculturally competent educator, there is an opportunity for undertaking selfexamination and for promoting more open public discourse. Similarly, for every barrier faced by students of color in their transition from school settings, there are potential solutions that can be facilitated by the informed special educator if he/she is aware of the barriers.

The Experience of Navajo Native Americans

Native American cultures provide some of the most striking examples of the challenges inherent in making postsecondary transitions. The overrepresentation of Native Americans among those diagnosed with learning difficulties (Fillmore, 1986) adds another layer of complexity to the transition process. Recent research on postsecondary transition among Native Americans highlights some of the challenges and points to some possible interventions. While it is dangerous to generalize from one Native American group to others, the experiences of Navajo Native Americans seem to be typical. The unemployment rate for individuals living on the Navajo reservation is about $30 \%$ (U.S. Bureau of the Census, 1990). Approximately 41\% of those living on the reservation have a high school degree (U.S. Department of Commerce, 1993). Only 5\% of Navajos have a bachelors degree or higher (U.S. Bureau of the Census, 1990). These low levels of 
employment and academic achievement are clearly related to the fact that $58 \%$ of the population live below the poverty level (U.S. Department of Commerce, 1993).

A study conducted by Jackson \& Smith (1999) investigated the experiences of 22 Navajo high school graduates from a small rural high school in the Four Corners area of the Southwestern United States. The participants were interviewed at their homes, on college campuses, and in their places of employment during the 2 years immediately following their graduation from high school. The researchers used a guided interview format (Patton, 1990) and a synthesis of interpretive qualitative approaches to analyze the transcribed interviews (Giorgi, 1985; Packer, 1985; Polkinghorne, 1984). The analysis yielded several themes relevant to the cross-cultural challenges involved in making postsecondary transitions, some of which are summarized below, along with related research findings.

Significant Relationships

Participants in the Jackson and Smith (1999) study focused on the importance of certain relationships in addressing their concerns about transitions: particular family relationships and faculty relationships. Participants were more confident about their transition and vocational prospects when they had a parent or close relative that had experienced success in these areas. Conversely, students whose close relatives had had little vocational success were less confident about their own prospects. Participants also mentioned high school faculty who had been particularly supportive and encouraging as key factors 
in their transition. Also faculty in postsecondary educational settings were seen either as nurturing mentors or as ominous barriers, depending on their relationship with the participants. Supporting research in this area suggests that both parents and mentors are of greater importance to Native Americans in making transitions than they are to their European American counterparts (Brown \& Kurpius, 1997; Lee, 1984). Limited Educational and Vocational Schema

According to Jackson and Smith (1999):

Participants demonstrated little understanding of postsecondary education and its relationship to specific careers. A few participants had clear educational paths they wanted to follow. However, most either did not have a clear understanding of what it would take to reach a career goal or did not have a career goal. ( $p .18)$

As they indicated, this uncertainty was demonstrated in four specific areas: "(1) misunderstanding the relationship of postsecondary training to careers, (2) vague postsecondary plans, (3) anxiety about taking educational and vocational risks, and (4) misunderstanding the relationship of careers to each other" (p.18).

Supporting research in this area suggests that students have vague educational and vocational perceptions when they receive limited information on vocations and limited exposure to different careers. Individuals with disabilities often have fewer vocational experiences over the course of their early 
development than do students without disabilities (Kosciulek, 1998; Martin, 1991). Gottfredsen (1981) theorized that cultures with lower socio-economic status might develop a cultural norm that exerts some pressure against advancing one's socioeconomic standing through educational or vocational achievement. She also argues that polarized gender roles and gender typing of vocations contributes to a limited view of vocational possibilities. Connection to Homeland and Culture

In the study of Navajo students' transitions, participants reported feeling uneasy and somewhat "disconnected" when they left their homeland to pursue work or educational opportunities. They also reported feeling confused about mixed messages to "(a) leave their reservation to be successful, and (b) maintain their traditional connection to their tribe, land, and culture" (Jackson \& Smith, 1999, p. 22). Participants also reported that they limited their exploration and consideration of vocations to those readily available to them on the reservation. This selfimposed restriction of considered vocations seemed to magnify the problem of an already limited amount of access to information about and exposure to a broad spectrum of possibilities.

Discrepancies between High School Culture and Postsecondary Culture

Participants in Jackson and Smith's (1999) study reported difficulty making the transition from their primarily Navajo high schools to more European American-dominant educational and 
vocational settings. This difficulty was manifest in a number of ways. Some participants reported struggling academically in their postsecondary settings despite their relative success as students in high school. Others reported difficulty adapting to the more demanding and punitive atmosphere of work and educational settings. One student described it as the difference between a nurturing mother and a demanding father. Evidence of this cross-cultural rift was also restricted in participants' reported feelings of isolation and loneliness in their transition process.

Research that supports this theme suggests that the more Native American students identify with European American culture, the more likely they are to effectively transition into European American-dominant culture (Morales, 1996). Unfortunately this finding seems to reflect the bias in the dominant culture as it appears to prescribe assimilation and homogeneity. An alternative hypothesis is that students who have identified with European American culture are more confident in their ability to thrive in that culture and that perhaps the issue is really cross-cultural self-efficacy rather than identification with European American culture (Kerbo, 1981). Some preliminary research is showing that identification with and pride in one's own culture may contribute to making effective transitions (Lamborn, et al., 1996). This view is supported by Braithewaite (1997) and others who have explored the transitions of students to tribal colleges, where persistence rates run as high as $88 \%(p .23)$. 


\section{Implications for Special Educators}

We present the following practical solutions for special educators working with students from diverse cultures in transition .

Significant Relationships

Successful programs that prepare students for adult society not only utilize school personnel but also involve members of diverse cultural communities in the preparation process (Campbell-Whatley, Algozzine, \& Obiakor, 1997). What communities can offer that schools often cannot provide is role models from the student's own cultural community to serve as mentors. This mentoring, from both parents and other community members, is an essential part of successful transition.

Involving interested family and friends in school to work transitions improves employment outcomes for students with disabilities (Hasazi, Gordon \& Roe, 1985). Family and community assistance is considered a best practice in effective transitions (Kohler, 1993; Wehman, 1990); these individuals help students find jobs, teach them what they need to do to be successful at the job, and support them when times are tough. Typically, students from diverse cultures may have limited social networks that lead to meaningful employment (Glover \& Marshall, 1993). 
In school-to-postsecondary training transitions of students from minority cultures, Jackson and Smith (1999) and others have emphasized the importance of faculty/student relationships (Astin, 1982; Braithewaite, 1997; Brown \& Kurpius, 1997; Lin, LaCount, \& Eder, 1988; Pascarella, 1980; Steward, 1993; Terenzini, Blimling, \& Pascarella, 1996). For example, a survey by Harris and Associates (1994) conducted with 360 young African American males, found that caring teachers (and involved parents) were the primary indicators of school-to-postsecondary training and school to work success. The literature on youth with disabilities and youth at risk of school failure is replete with recommendations for building positive relationships.

Too often, an educator's focus on learning can impede quality relationships. For example, a university student in a multicultural issues class was tutoring a student of color for a service learning assignment. The tutor expressed frustration that the student continually engaged in avoidance behaviors to escape learning to read. Finally the tutor gave up trying to force the tutee to do academics and talked to the student informally. They soon grew to like each other, and as the relationship improved, the student desired to please the tutor by learning to read.

All three of these elements (parental and friend involvement, mentoring relationships, and improved 
faculty/student relationships) are factors teachers have some control over and can foster for their students from diverse cultures during transition.

Educational and Vocational Perceptions

Jackson and Smith (1999) found that most Navajo students did not have a clear idea of what to do in order to reach the particular career goal they had identified as desirable.

Students knew they needed a degree to pursue a career, but they were unfamiliar with what career required what degree. They were also uncertain about what was expected of them in order to acquire that degree.

Morningstar, Turnbull, and Turnbull (1996) found that families were the major resources for future planning for students with disabilities and that planning was, at best, informal. Teachers and mentors can also be major resources for future planning. Time should be spent with the student assessing vocational interests and abilities, presenting career options, recognizing training necessary for a desired career, helping the student understand and commit to what is required to reach that career goal, and fostering mentoring relationships in the new school or work environment. Future planning should also include discussing what possible cultural conflicts might arise and how to resolve them in the worlds of postsecondary training and work. 
Limited educational and vocational schema of students from diverse cultures who are in transition can be improved upon. Teachers and mentors need to assist the student with future planning.

Connection to Homeland and Culture

One consideration in transitions suggested by Jackson and Smith (1999) is that of students' connections to their homelands and cultures. A major decision that students in transition must make is whether they want to be employed in their home community after high school or postsecondary training. If the answer is yes, career options will be restricted to what is available in that community or to what that community needs. Teachers, mentors, and parents should assist students in deciding whether they want to return to their home communities or whether they are open to a greater range of geographic and cultural options. Knowing the cultural context in which a student will live and work will help the teacher and the student determine what social skills and vocabulary must be mastered during transition in order for the student to succeed in the new environment. The practice of systematically observing behaviors in the environment in which a student will be living, working, or attending school is called situational assessment (Sitlington, Clark, \& Kolstoe, 2000). Teachers use situational assessment to determine specific behaviors a student needs to learn.

Discrepancies between High School Culture and Postsecondary Culture 
Cultural conflict may occur between the student and others at several junctures along the transition path. Home or street cultures often conflict with school cultures or work cultures, but high school and postsecondary school cultures also conflict, according to Navajo informants (Jackson \& Smith, 1999). If the high school a student attended involved primarily students or educators from a culture besides European American, the European American nature of both the postsecondary educational institutions and the workplace may require the student to make significant cultural adjustments. Even if the cultural composition of students in high schools and postsecondary training institutes is comparable, the two institutions will differ in their behavioral expectations.

Teachers must help students address and not ignore these possible cultural conflicts in order to prevent failure. Some Navajo students in postsecondary schools reported struggling academically; some reported feeling isolated. Students must be clearly aware of what will be required of them academically in a postsecondary setting and have the opportunity to practice those skills in high school before they have to perform them after high school. Students should be helped to find out how many individuals from a culture similar to their own attend the school and what social support systems are available. If culture 
is important to them, they should make an informed decision about which school to attend.

Research Concerns

of concern to educators and others involved in the transition process is the relative paucity of research specific to issues that students of color face in the schools and in their transition to other settings. Published research often determines what will be taught and which interventions will be used. However, because the majority of special education research has been conducted with populations that are predominantly Caucasian or has categorized students according to disability category and not culture, limited data are available to help researchers and practitioners ensure that appropriate services are provided to students from different backgrounds. Such limitations may reflect subtle cultural biases present in larger society (McConahay, 1985), but even if they are unintentional, such misrepresentations clearly compromise the quality of the field.

To respond to this concern, three strategies may prove useful. First, publishers and editorial boards should carefully consider the external validity of the research they review (Sue, 1999). Results of a study or descriptions of a technique should always detail the limitations of generalization to other settings. For example, the Navajo study cited in this article was limited in 
that it only looked at members of one tribe of Native Americans. Accordingly, generalization to other cultures, even to other Native Americans, should be tentative. Second, researchers should accurately report the demographic composition of their participants and routinely conduct analyses to verify that the results presented are similar across all groups. And third, researchers should utilize strategies to recruit participants from underrepresented groups. For example, techniques that have been used to successfully recruit participants of Hispanic origin for studies include advertising in both English and Spanish, incorporating social networking strategies, utilizing face-to-face recruitment, providing transportation and childcare, and placing reminder phone calls (e.g., Hooks, Tsong, Henske, Baranowski, \& Levin, 1986).

\section{Conclusions}

Evidence suggests that students from culturally diverse backgrounds have more difficulty making postsecondary transitions than students from the dominant culture. our examination of Native Americans' transition experiences demonstrates how ethnic diversity may impact transitions. We have also cited evidence that shows how students with disabilities are at greater risk in making transitions from high school. Students with culturally diverse backgrounds and disabilities are challenged on both dimensions, and their risk seems to multiply exponentially. The research on transitions 
indicates that the risks in transition may be minimized by a number of strategies:

1. Attending to significant relationships that impact transitions. This includes faculty, family, peers, and particularly relationships with mentors with whom the student can relate and use as models for transition success.

2. Providing clear information and significant exposure to the world of work in general and to occupations of interest in particular. This provides students with the information necessary to develop a realistic and hopeful perception of how they might fit into postsecondary settings.

3. Demonstrating awareness of and respect for students' cultural backgrounds. This helps students to develop a positive cultural identity and to see their cultural background as an asset.

4. Providing supportive services and orienting students to these supports. Such supports would include multicultural, academic, and disability services on campuses and within organizations; social support networks; and culture-specific groups such as clubs, churches, and political organizations. Again, effective mentors can facilitate access to much of the available support.

Facilitating successful transitions for culturally diverse students requires a concerted effort by family, school, and community members. Such concerted effort requires each party to be aware of cultural differences and of their own biases. It also requires the courage to cooperatively address the inherent 
social barriers that impede the transitions of culturally diverse students. 


\section{References}

Astin, A. A. (1982). Minorities in American higher education. San Francisco: Jossey-Bass.

Baca, L. M., \& Cervantes, H. T. (1998). The bilingual special education interface (3rd ed.). Upper Saddle River, NJ: Prentice-Hall.

Bakken, J. P., \& Aloia, G. F. (1999). Transitioning multicultural learners with exceptionalities. In F. E. Obiakor, J. 0. Schwenn, \& A. F. Rotatori (Eds.), Advances in special education: Multicultural education for learners with exceptionalities (pp. 217-232) Stamford, CT: JAI Press.

Braithwaite, C. A. (1997, November-December). Helping students from tribal colleges succeed. About Campus, 2, 19-23.

Brown, L. L., \& Kurpius, S. E. (1997). Psychosocial factors influencing academic persistence of American Indian college students. Journal of College Student Development, 38, 3-12.

Campbell-Whatley, G. D., Algozzine, B., \& Obiakor, F. (1997). Using mentoring to improve academic programming for African American male youths with mild disabilities. The School Counselor, 44, 362-366.

Easter, L. M., Shultz, E. L., Neyhart, T., \& Reck, U. (1999). Weighty perceptions: A study of the attitudes and beliefs of preservice teacher education students regarding diversity and urban education. Urban-Review, 31, 205-220. 
Fillmore, L. W. (1986). Teaching bilingual learners. In M. C. Wittrock (Ed.), Handbook of research on teaching (3rd ed.) (pp. 648-685). New York: Macmillan.

Gibson, M. A. (1988). Accomodation without assimilation: Sikh immigrants in an American high school. Ithaca, NY: Cornell University Press.

Giorgi, A. (Ed.). (1985). Phenomenology and psychological research. Pittsburgh, PA: Duquesne University Press.

Glover, R. W., \& Marshall, R. (1993). Improving the schoolto-work transition of American adolescents. Teachers College Record, 94, (3), 588-610.

Gottfredson, L. S. (1981). Circumscriptions and compromise: A development theory of occupational aspirations [Monograph]. Journal of Counseling Psychology, 28, 545-579.

Harris \& Associates (1994). Pilot survey of young African American males in four cities. New York: Commonwealth Fund. Hasazi, S. B., Gordon, L. R., \& Roe, C. A. (1985). Factors associated with the employment status of handicapped youth exiting high school from 1979 to 1983. Exceptional Children, 51, 445-469.

Hooks, P. C., Tsong, Y., Henske, J. C., Baranowski, T., \& Levin, J. S. (1986). Social networking as a recruitment strategy for Mexican American families in community health research. Hispanic Journal of Behavioral Sciences, 8, 345-355. 
Howitt, D., \& Owusu-Bempah, K. (1999). Education, psychology and the construction of Black childhood. Educational and Child Psychology, 16(3), 17-29.

Hoyt, K. B. (1998). The changing workforce: A review of projections--1986 to 2000. The Career Development Quarterly. 37, 31-39.

Individuals with Disabilities Education Act, 20 U.S.C. 1414.

Individuals with Disabilities Education Act Amendments of 1997 Regulations, 34 C.F.R. 300 et.seq.

Jackson, A. P., \& Smith S. A. (1999). Postsecondary transitions among Navajo Native Americans. Manuscript submitted for publication.

Katz, J. H., \& Torres, C. (1983). Combatting racism in education: A White awareness approach. Early Child Development and Care, 10, 333-344.

Kerbo, H. R. (1981). College achievement among Native Americans: A research note. Social Forces, 59, 1275-1280.

Kohler, P. D. (1993). Best practices in transition: Substantiated or implied? Career Development for Exceptional Individuals, 16, 107-120.

Kosciulek, J. (1998). Empowering the life choices of people with disabilities through career counseling. In N. C. Gysbers, 
M. H. Heppner, \& Joseph A. Johnston (Eds.), Career counseling: Process, issues, and techniques. Boston: Allyn \& Bacon. Lamborn, S., Solberg, V. S., Torres, J., Gusavac, N., Hamman, T., Pogoriler, D., Felch, J., Metz, A. J., \& Rodriguez, M. (August, 1997). The role of family and ethnicity factors on college outcomes. Paper presented at the $105^{\text {th }}$ Annual Meeting of the American Psychological Association, Chicago.

Lee, C. C. (1984). Predicting the career choice attitudes of rural Black, White, and Native American students. Vocational Guidance Quarterly, 32(3), 177. Martin, W. E. (1991). Career development and American Indians living on reservations: crosscultural factors to consider. Career Development Quarterly, 39, $273-283$.

Lin, R., Lacount, D., \& Eder, J. (1988). A study of Native American students in a predominantly White college. Journal of American Indian Education, 27, 8-15.

McIntosh, P. (1998). White privilege: Unpacking the invisible knapsack.

In M. McGoldrick (Ed.) Re-visioning family therapy: Race, culture, and gender in clinical practice. (pp. 147-152) New York: The Guilford Press.

Minnesota Private College Research Foundation (1994). Divided we fall: The declining chance for college among Minnesota youth from low-income families and communities of color. St Paul: Author. 
Morales, P. C. (1996, August). Acculturation and vocational identity: The influence of Hispanic familialism. Paper presented at the 104th Annual Meeting of the American Psychological Association, Toronto, Canada.

Morningstar, M. E., Turnbull, A. P., \& Turnbull, M. R. (1996). What do students with disabilities tell us about the importance of family involvement in the transition from school to adult life? Exceptional Children, 62,(3), 249-260.

National Council of Juvenile and Family Court Judges (1990). Minority youth in the juvenile justice system. Juvenile and Family Court Journal, 41(3A), 1-60.

Obiakor, F. E. (1999). Multicultural education: Powerful tool for educating learners with exceptionalities. In F. E. Obiakor, J. 0. Schwenn, \& A. F. Rotatori (Eds.), Advances in special education: Multicultural education for learners with exceptionalities. (pp. 1-14). Stamford, CT: JAI Press.

Ornstein, A. C., \& Levine, D. U. (1989). Social class, race, and school achievement: Problems and prospects. Journal of Teacher Education, 4, (5), 17-23.

Packer, M. J. (1985). Hermeneutic inquiry in the study of human conduct. American Psychologist, 40, 1081-1093.

Pascarella, E. T. (1980). Student-faculty informal contact and college outcomes. Review of Educational Research, 50, 545595.

Patton, M. Q. (1990). Qualitative evaluation and research methods ( $2^{\text {nd }}$ ed. $)$. Newbury Park, CA: Sage. 
Polkinghorne, D. E. (1984). Further extensions of methodological diversity for counseling psychology. Journal of Counseling Psychology, 31, 416-429.

Sitlington, P. L., Clark, G. M., \& Kolstoe, 0. P. (2000). Transition education and services for adolescents with disabilities ( $3^{\text {rd }}$ ed.). Needham Heights, MA: Allyn \& Bacon.

Smith, D. D. (1998). Introduction to special education: Teaching in an age of challenge ( $3^{\text {rd }}$ ed.). Needham Heights, MA: Allyn and Bacon.

Steward, R. J. (1993). Two faces of academic success: Case studies of American Indians on a predominately Anglo university campus. Journal of College Student Development, 34, 191-196.

Sue, D. W., \& Sue, D. (1999). Counseling the culturally different: Theory and practice ( $3^{\text {rd }}$ ed.). New York: Wiley.

Sue, S. (1999). Science, ethnicity, and bias: Where have we gone wrong? American Psychologist, 54, 1070-1077.

Terenzini, P. T., Blimling, G. S., \& Pascarella, E. T. (1996). Students' out-of-class experiences and their influence on learning and cognitive development: A literature review. Journal of College Student Development, 37, 149-162.

U.S. Bureau of the Census. (1990). Characteristics of American Indians by tribe and selected areas. Washington, DC: U.S. Government Printing office. 
U.S. Department of Commerce (1993). We the first Americans. Washington, DC: U.S. Government Printing Office.

IDEA (1990). Individuals with Disabilities Act of 1990, Pub. L. No. . .

IDEA (1997). Individuals with Disabilities Act Amendments of 1997, Pub. L. No. 105-17. June 4, 199720 U. S. C., 1412.

Voltz, D. L. (1998). Cultural diversity and special education teacher preparation: Critical issues confronting the field. Teacher Education and Special Education, 21,(1), 63-70. Wehman, P. (1990). School-to-work: Elements of successful programs. Teaching Exceptional Children, 23, 40-43. Winzer, M. A., \& Mazurek, K. (1998). Special education in multicultural contexts. Upper Saddle River, NJ: Prentice-Hall. 
Author Note

Lynn Wilder, Department of Counseling Psychology and Special Education; Aaron P. Jackson, Department of Counseling Psychology and Special Education; Timothy B Smith, Department of Counseling Psychology and Special Education. 
Correspondence concerning this article should be addressed to Lynn Wilder, Brigham Young University, 332-F MCKB, P0 Box 25043, Provo, UT 84602-5043. E-mail may be sent to lynn_wilder@byu.edu. 